\title{
Formulation, Solid State Characterization and Enhancement of Dissolution Rate of Olmesartan Medoxomil by Polyvinyl Alcohol-Polyethylene Glycol Graft Copolymer Based Nanoparticles
}

\author{
Aparna Ashok chavan, Amol Somanath Shete*, Bhagyesh Uttamrao Janugade, Rajendra \\ Chandrashekar Doijad
}

Research Group Department of pharmaceutics and Quality Assurance, Shree Santkrupa College of Pharmacy, Ghogaon, Karad-415111, INDIA.

\begin{abstract}
The objectives of present investigation were to prepare and evaluate nanoparticles of Olmesartan medoxomil (OLM) by a precipitation method using polyvinyl alcoholpolyethylene glycol graft copolymer (Kollicoat IR) and to investigate the effect of stirring speed \& time on particle size. Particles were characterized for drug content, FTIR, zeta potential (ZP), particle size distribution (Dynamic light scattering), differential scanning calorimeter (DSC), powder X-ray diffraction (PXRD), scanning electron microscopy (SEM), solubility, in vitro release and stability studies. All batches showed drug content in range of $93.24 \pm 0.96 \%$ to $99.91 \pm 0.98 \%$, particle size in range of $136.3-188.9 \mathrm{~nm}$. As stirring speed increased particles of reduced size obtained and vice versa. ZP values of formulations were from $-2.28 \mathrm{mV}$ to $-17.90 \mathrm{mV}$ \& comply with requirement of ZP for stability. Solubility results indicated improvement in solubility of formulations. PXRD analysis showed particles were in same crystalline state as raw OLM. Particle exhibited enhanced dissolution compared to raw material due to reduction in particle size, increased surface area \& solubility. When formulated in tablets showed improvement in dissolution, compared to marketed formulation, anti solvent precipitation method is promising tool to prepare OLM particles by using Kollicoat IR as a polymer, for enhancement of solubility, dissolution velocity of OLM.
\end{abstract}

KEY WORDS: Drug nano particles, Anti solvent method, Olmesartan medoxomil, Kollicoat IR, Solubility and Dissolution.

\section{INTRODUCTION}

In development of new chemical entities as successful drugs aqueous solubility is a one of the key determinant. For oral absorption new chemical entities are required to possess physicochemical characteristics that results in acceptable absorption, Butnumber of candidates needs physicochemical modification or special formulation technology. ${ }^{1}$ Various companies has developed a various technologies and they realized that these are not a functional. Literature reveals various solublization technologiese. g. solubilisation by using surfactants, formulation of molecular complexes, solid dispersions etc. are applied to overcome solubility they are unable to solubilize molecules and suffers from major drawbacks of stability and principle limitations of these approaches is drug needs to possess certain physicochemical properties. Micro/Nanoparticles
Submission Date : 05-07-2016 Revision Date : 23-08-2016 Accepted Date : 01-09-2016

DOI: 10.5530/ijper.50.4.20 Correspondence: Mr. Shete Amol Somanath, Head \& Assistant professor Department of Pharmaceutics Shree Santkrupa College of Pharmacy, Ghogaon Tal. Karad, Dist. Satara, M.S. (INDIA)

Phone no. 09822916129

E-mail: amol.shete@rediffmail.com

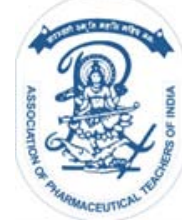

www.ijper.org 
became one option to 'save' molecule for market and overcomes limitations of other technologies. ${ }^{2}$

Particulate delivery systems have become important in experimental pharmaceutics and clinical medicine; it acts as a carrier for small and large molecules. Particulate systems like micro/nanoparticles have been used as physical approach to alter and improve pharmacokinetic, pharmacodynamics properties of various types of drug molecules. The distinction is often made between micro- and nano particles, being particles with dimensions best described in micrometers and nanometers respectively. In micronization particle size reduces to 1-10 micrometer. ${ }^{3}$ Drug nano particles are pure solid drug particles with mean diameter below 1000 nm. Katteboinaa, Chandrasekhar and Balaji et al. states that "depending on discipline, e.g. in colloidal chemistry particles are only considered as nanoparticles when they are in size below $20 \mathrm{~nm}$. But based on size unit in pharmaceutical area, nanoparticles should be defined as having size below $1000 \mathrm{~nm} "{ }^{4}$

In case of nanoparticles particle size is reduced to about $100 \mathrm{~nm}$ there is drastic change in properties of material. The decreased particle size, increases surface area and solubility of drug manifolds and there is a proportionate increase in bioavailability. It increases not only surface area but also saturation solubility. Nano suspension is an alternative approach for formulation is dispersion of drug nanoparticles in liquid media but stability is the problem with dispersed particles. ${ }^{5}$

Many techniques have been used to produce particulate drug delivery system including mechanical commutation, ${ }^{6}$ supercritical fluid technique ${ }^{7}$ and anti solvent precipitation process. ${ }^{8}$ Mechanical commutation methods need high-energy input and show some disadvantages in practice like electrostatic effects, broad particle size distributions. ' Supercritical fluid technique is attractive methods for size reduction, providing particles with narrow size distribution. But, they also have limitations of low yield and high equipment cost. ${ }^{10}$ Anti solvent precipitation process is promising technique to prepare drug particles, which is based on change of super saturation caused by mixing solution and anti solvent. In this method, it requires two solvents that are miscible. ${ }^{11}$ Ideally, drug must dissolve in solvent, but not in anti solvent. Precipitation occurs instantaneously by rapid desolvation of drug. Key to producing particles with reduction in size by anti solvent precipitation is to create conditions that favor very rapid particle formation and little particle growth. Technique presents some advantages, in that it is straightforward method, rapid and easy to perform.
Chemically Olmesartan medoxomil is 4-(1-Hydroxy1-methylethyl)-2-propyl-(1H-tetrazol-5 yl) [1,1'-biphenyl]4-yl]methyl- 1H-imdiazole-5-carboxylic acid (5-methyl2-oxo-1,-3- dioxol-4-yl)methyl ester.OLM is angiotensin-II receptor antagonist that is approved for treatment of hypertension. It dose dependently reduces blood pressure through arterial vasodilation and reduced sodium retention. It is pro drug that is rapidly de-esterified during absorption from gastrointestinal tract to produce active metabolite. Aqueous solubility of OLM is $<7.75 \mu \mathrm{g} / \mathrm{ml}$. It is practically insoluble in water and soluble inorganic solvents. Oral bioavailability is only $26 \%$ in healthy humans due to low aqueous solubility, unabsorbed drug leads to gastrointestinal side effects such as abdominal pain, dyspepsia, gastroenteritis and nausea. ${ }^{12}$

The objectives of present work were to prepare nano particles by anti solvent precipitation method by using Polyvinyl Alcohol- Polyethylene Glycol Graft Copolymer (Kolicoat IR), characterize prepared particles for drug content uniformity, scanning electron microscopy, particle size distribution by (dynamic light scattering),zeta potential, X-ray powder diffraction study, differential scanning calorimetry, drug interaction studies by Fourier transform infrared spectroscopy, Solubility, in-vitro release study. To incorporate nanoparticles in tablets and evaluation of tablets, compare in-vitro release study of prepared tablets with marketed formulation and evaluate particles for stability.

\section{MATERIALS AND METHODS}

\section{Materials}

Olmesartan Medoxomil was a gift sample from Emcure Pharmaceuticals Ltd, Pune. Kollicoat IR were kind gift from Lupin Pharmaceuticals Ltd, Pune, Lactose monohydrate, Microcrystalline cellulose(MCC, Avicel pH-102), Cross carmellose sodium (Ac-Di-Sol), Magnesium stearate, Talc, were Pharma grade and obtained from Emcure Pharmaceuticals Ltd, Pune. Ethanol was Laboratory grade and obtained commercially from Oasis Alcohol Pvt Ltd, Tasavade. Marketed formulations of Olmesartan Medoxomil tablets were purchased from local drug store in karadcity after checking their manufacturing, production and expiry date. All other reagents were of analytical grade.

\section{Preparation of Nanoparticles;}

Experimental process for preparation of OLM particles;in short, ethanol and water were used as solvent and anti solvent of OLM respectively. Raw OLM was dissolved in ethanol and solution was filtered through membrane filter with pore size of $0.45 \mu \mathrm{m}$ to remove 
possible particulate impurities. Kollicoat IR added into $10 \mathrm{~mL}$ of water, used as initial antisolvent.OLM ethanol solution was added drop wise in water with vigorous stirring speed of $1500 \mathrm{rpm}$, by using magnetic stirrer (Remi Equipment's Ltd. MLH. India). Immediately particles precipitated from anti solvent and a milk-like suspension was formed spontaneously. After stirring for 5 min, suspension was filtered through membrane filter $(0.45 \mu \mathrm{m})$, residue was dried in hot air oven (Dolphin India.) at $60^{\circ} \mathrm{C}$ for 1 day. Prepared formulations were stored at ambient conditions until further use. Composition of drug particles is shown in Table 1.

\section{Characterization of nanoparticles Micromeritic properties}

The sample of OLM and obtained particles of OLM was evaluated for flow properties like angle of repose, bulk density (Make- Electrolab, TDT- 06P, Mumbai.) and tapped density, Carr's index, hausner's ratio.

\section{Solubility analysis in different solvents}

Solubility studies of OLM and prepared OLM particles were carried out according to method reported by [Higuchi and Connors].Excess quantity of OLM wastransferred in $20 \mathrm{~mL}$ capacity conical flask containing $10 \mathrm{ml}$ (water, $0.1 \mathrm{~N} \mathrm{Hcl}$, Citrate buffer, Phosphate buffer pH 5.8 and 6.8) covered with aluminum foil, sonicated (Dolphin India) for $30 \mathrm{~min}$. The flasks were shaken on rotary orbital shaker for 24 hrs. Flask was removed and stabilized for $1 \mathrm{hr}$. Content of each flask was then filtered through Whatmanfilter paper (No. 41). Filtrate was diluted and assayed spectrophotometricaly (Shimadzu Corporation, Japan) at $257 \mathrm{~nm}$. Solubility was determined in triplicate $(\mathrm{n}=3)$

\section{Study of effect of variables on particle size Effect of stirring time}

Stirring time was usually important factor to influence on particle size in anti solvent precipitation process. Relationship between particle size and stirring time was studied during formulation of drug particles. Formulations were kept for different stirring time $(5,10,15 \mathrm{~min})$ and particle size of each formulation was examined by using scanning electron microscopy (JEOL, JSM 50A, Tokyo, Japan.)

\section{Effect of polymer concentration}

Effect of polymer concentration (Kollicoat IR) on particle size was investigated by preparing drug particles with increasing order of their concentration and evaluated for particle size by using scanning electron microscopy (JEOL, JSM 50A, Tokyo, Japan.)

\section{Determination of Particle Size and particle size distribution (PSD)}

Particle size and PSD of particles were determined by dynamic light scattering (NICOMP 380ZLS PSS NICOMP Particle sizing systems Santa Barbara, California USA.) Sample were diluted with three times of water and sonicated to create a homogeneous suspension this diluted suspension was added to sample cell (quartz cuvettes) and put into sample holder unit measurement was carried out in triplicate.

\section{Zeta Potential Analysis}

Zeta potential of particles was determined by dynamic light scattering (NICOMP 380ZLS PSS NICOMP Particle sizing systems Santa Barbara, California USA.) Samples were diluted with three times of water to get a homogeneous suspension, this diluted suspension was added into specialized zeta (electrophoretic cell) and put into sample holder unit were an electric field was applied. Measurement was carried out in triplicate.

\section{Drug content determination}

Drug content of particles were determined by weighing $10 \mathrm{mg}$ particles from each formulation, transferred it into volumetric flask and added $100 \mathrm{ml}$ of phosphate buffer $\mathrm{pH}$ 6.8. Resultant solution was sonicated for $10 \mathrm{~min}$ and filtered through Whatmanns filter paper (No. 41). Suitable volume of filtrate was diluted with sufficient quantity of phosphate buffer $\mathrm{pH}$ 6.8. Absorbance was measured at $257 \mathrm{~nm}$. Content of OLM was calculated. Sample was analyzed in triplicate. Drug content was calculated for all batches using equation as follows:

$$
\text { Drug Content }=\mathrm{O}_{\mathrm{act}} / \mathrm{O}_{\mathrm{ss}} \times 100
$$

$\mathrm{O}_{\text {act }}$ : Actual Olmesartan medoxomil content in weight quantity of particles.

$\mathrm{O}_{\mathrm{ss}}$ : Theoretical amount of olmesartan medoxomil particles.

\section{Drug- Excipients Compatibility Studies (FTIR studies)}

FTIR spectra of Olmesartan medoxomil and physical mixture (OLM: Kollicoat IR) and formulation F4 was obtained by using ShimadzuFTIR-8400S spectrophotometer with IR solution software (Shimadzu). Samples were dried under vacuum in order to remove influence of residual moisture. Samples prepared by grinding small amount of sample and corresponding amount of potassium bromide (1:100) in agate mortar and pressed into self-supporting disks. Data were collected over a spectral region from 4500 to $400 \mathrm{~cm}^{-1}$ with resolution of $4 \mathrm{~cm}^{1}$ and 45 scans. 


\section{Powder X-ray diffraction}

Crystalline state evaluation of pure OLM, Kollicoat IR and formulation was done by using Powder X-Ray Diffraction. PXRD diffractograms of samples were analyzed using an X-ray Diffractometer (D2 Phaser, Bruker.) with $\mathrm{Cu}-\mathrm{K} \alpha$ radiation at wavelength of $1.542 \AA$, generated at $30 \mathrm{~mA}$ current, and $40 \mathrm{kV}$ voltages. Samples were analyzed in $2 \theta$ range from $5^{\circ}$ to $50^{\circ}$ using step size of $0.02^{\circ}$.

\section{Differential scanning calorimetry}

Thermal properties of powder were investigated with Perkin-Elmer DSC-4 DSC. Amount of product to be analyzed shall range from 4 to $7 \mathrm{mg}$ and placed in perforated aluminum sealed $50 \mu \mathrm{l}$ pans. Heat runs for sample was set from $50-300^{\circ} \mathrm{C}$ at scanning rate of $10^{\circ} \mathrm{C} / \mathrm{min}$, an inert environment was maintained under dry nitrogen flow $(100 \mathrm{ml} / \mathrm{min})$. The apparatus was calibrated using pure metal like Indium with known melting points and heat of fusion.

\section{Scanning electron microscopy}

Particle morphology was observed using SEM (JEOL, JSM 50A, Tokyo, Japan.) Appropriate amount of OLM powder or glass slide with small drop of the suspension, were fixed on an SEM stub using double-sided adhesive tape and coated with $\mathrm{Au}$ at $50 \mathrm{~mA}$ for $6 \mathrm{~min}$ through sputter-coater (KYKY SBC-12, Beijing, China). SEM with secondary electron detector was used to obtain digital images of samples at an accelerating voltage of $10 \mathrm{kV}$.

\section{In vitro dissolution Study}

In vitro dissolution studies were carried out for pure OLM \& all formulations by using USP type II apparatus (VDA 6D USP STANDARDS VEEGO.) $40 \mathrm{mg}$ of pure OLM and equivalent amount of OLM particles were used for dissolution studies. $900 \mathrm{ml}$ of Phosphate buffer $\mathrm{pH} 6.8$ was used as dissolution medium maintained at $37 \pm 0.5^{\circ} \mathrm{C}$ and stirred at $50 \mathrm{rpm} .5 \mathrm{~mL}$ of aliquot were withdrawn at predetermined intervals \& filtered usingWhitman filter paper (No. 41). An equal volume of dissolution medium was replaced after each withdrawal to maintain sink condition, dilutions were made with phosphate buffer pH 6.8 \&samples were analyzed by UV spectro photometricaly at $257 \mathrm{~nm}$ against phosphate buffer $\mathrm{pH}$ 6.8.Cumulative $\%$ of drug released was calculated \& plotted against function of time.Each test was performed in triplicate $(\mathrm{n}=3)$.

\section{Development of Tablet dosage form \\ Preparation of powder blends for tablets}

Powder blend for tablets was prepared using drug particles (equivalent to $40 \mathrm{mg}$ ), Lactose monohydrate used as diluent, microcrystalline Cellulose (MCC, Avicel PH-102) as a diluents and disintegrant, Cross-carmellose Sodium (Ac-Di-Sol) acts as a super disintegrant. All above ingredients were dry blended for $20 \mathrm{~min}$, followed by addition of magnesium stearate (lubricant). Mixtures were then further blended for $10 \mathrm{~min}$.

\section{Formulation of tablets}

Composition of tablets is shown in Table 4. Direct compression method was used to prepare tablets. Resultant powder blend of OLM, Lactose monohydrate, Microcrystalline Cellulose (MCC, Avicel PH-102), Crosscarmellose Sodium (Ac-Di-Sol) was manually compressed using $\mathrm{KBr}$ hydraulic press (Model M-15.Technosearch instruments, India.) at a pressure of 1 ton, with $8 \mathrm{~mm}$ punch and die to obtain tablets.

\section{Evaluation of tablets}

The prepared tablets were evaluated for official and unofficial evaluation parameters like thickness, hardness, weight variation and friability were measured. Thickness of tablets were determined byusing Vernier caliper (Rajesh chemicals, Mumbai) and hardness by using Pfizer hardness tester. Weight Variation was calculated by selecting twenty tablets randomly. Tablets were weighed individually and average weight was calculated. Friability was calculated as \% weightloss of 6 tablets after 100 rotations using friability test apparatus (Roche) Each test was per formed in triplicate $(n=3){ }^{13}$

\section{Comparison of In vitro dissolution profile of prepared tablets (OLM particles) and marketed formulation (olsertain ${ }^{\mathrm{TM}} 40$ )}

In vitro dissolution studies were carried out for tablets (OLM Nanoparticles of Optimized batch F4) and marketed formulationaccording to method reported in for nanoparticles.

\section{Stability study}

Stability study was performed to determine change in physical characteristics like colour, drug content, dissolution behaviour, on storage at room temperature for 3 months. Every month sample was withdrawn and evaluated. 


\section{RESULTS AND DISCUSSION}

\section{Micromeritic properties}

Flow ability of Olmesartan medoxomil was good reflected by values of angle of repose, Carr's index and Hausner's ratio, bulk density, tapped density.The angle of repose of OLM was found to be $33.16 \pm 0.83^{\circ}$ categorized as good flowing. Bulk and tapped density was found to be $0.4169 \mathrm{gm} / \mathrm{cm}^{3}, 0.4761 \mathrm{gm} / \mathrm{cm}^{3}$ respectively. Hausner's ratio and Carr's index was found to be 1.14 and $12.4343(\%)$ respectively indicated that OLM has good flow properties. Angle of repose of the formulation F1, F2, F3, F4 was found to be $30.61,29.74,28.92,28.65^{\circ}$ respectively. Bulk and tapped density of formulation F1, F2, F3, F4 was found to be $0.4201,0.4110,0.4000,0.4347$ $\mathrm{gm} / \mathrm{cm}^{3}$ and $0.4663,0.4545,0.4347,0.4505 \mathrm{gm} / \mathrm{cm}^{3}$ respectively. Hausner's ratio and Carr's index of formulation F1, F2, F3, F4 was found to be 1.109, 1.105, 1.08, 1.03 and $9.9077,9.570,7.9825,3.5072(\%)$ respectively. It indicated significant reduction in values of angle of repose and Carr's index of particles compared to original drug. OLM had significantly higher angle of repose in comparison to particles which might be due to irregular shape of pure OLM and put barrier in uniform flow particles from funnel. The perfect shape and larger sizeof particles decreased interparticle friction and it could be suggested as one of the reason for easy and uniform flowof particles leading to excellent flow ability of OLM particles. ${ }^{13}$

\section{Solubility analysis in different solvents}

Solubility of OLM in various solvents is summarized in Table 2 OLM showed very poor solubility in water and phosphate buffer pH5.8 and high solubility in $0.1 \mathrm{~N} \mathrm{Hcl}$. The results (Figure 1) indicated that OLM was sparingly soluble in strong acids.Solubility of OLM particles showed drastic improvement in solubility of formulation in water as compared to pure OLM also increased solubility into other solvents. Solubility of formulation was increased due to reduction in particle size, increased in surface area of drug (Noyes-Whitney equation) also; it increased due to Kollicoat IR used as polymer (which is hydrophilic in nature). ${ }^{14}$

\section{Effect of variables on particle size Effect of stirring time}

The relationship between particle size distribution and stirring time is revealed in Figure 2 Formulation was kept for different stirring time. (5, 10,15min) Stirring time is important factor to influence particle size in anti solvent precipitation process. It is evident that there is notable increase in particle size with increase in stirring time. This can be explained by particle growth. When
OLM ethanol solution was added into aqueous solution, small particles are formed immediately. During stirring process, formed small particles would collide \& aggregate together, which may cause particle growth to larger ones. It can be found that OLM particles own narrow size distribution under shorter stirring time. Therefore, stirring for $5 \mathrm{~min}$ was believed as an optimum condition to obtain small particles. ${ }^{15}$

\section{Effect of polymer concentration}

Effect of Kollicoat IR concentration on OLM particle size is shown in Figure 3. It was investigated by preparing drug particles with increasing order of their concentration. Results indicated Kollicoat IR molecules were adsorbed onto formed hydrophobic drug particle surface and has good affinity for drug particles and able to provide effective barrier against growth. When 0.25 , $0.5,0.75,1 \%(\mathrm{w} / \mathrm{v})$ Kollicoat IR were added into water. Particles size was dramatically decreased with $1 \%(\mathrm{w} / \mathrm{v})$ concentration of polymer. After that, particles size was not significantly influenced by increasing Kollicoat IR concentration, which indicates that drug particle surface is already sufficiently enveloped by Kollicoat IR molecules. This indicating that Kollicoat IR was plays key role in controlling morphology \& size of OLM particles. ${ }^{16}$

\section{Determination of Particle Size and particle size distribution (PSD)}

Particle size distribution graphs showed in Figure 4 Particle size of formulations showed in Table 3. Poly dispersivity index is measure of width of distribution. PDI below 0.5 indicating narrow PSD. PDI index of Formulation F1, F2, F3, F4 was (0.452, 0.546, 0.560, 0.299) indicating F4 formulation showed narrow particle size distribution as compared to other formulations.In micronization size ranges from $1-10 \mu \mathrm{m}$ \& nanonization size ranges from 1-1000 nm. Results of PSD showed all formulations were found in range of nanometer. Four different formulations were prepared with different concentration of Kollicoat IR. Highest concentration of polymer containing formulation $\mathrm{F} 4$ showed smallest particle size. This might be due to use of high concentration of polymer and also may be due to polymer contains hydroxyl groups, which can form hydrogen bonds between drug \& polymer. Polymer, presented in aqueous solution absorbed on surface of formed drug particles to inhibit particle growth \& controlling size of OLM. ${ }^{4}$

\section{Zeta Potential Analysis}

ZP of Formulation was found to be F1, F2, F3, and F4 (-2.28, -9.77, -11.05, -17.90 mV resp.) Kollicoat IR 


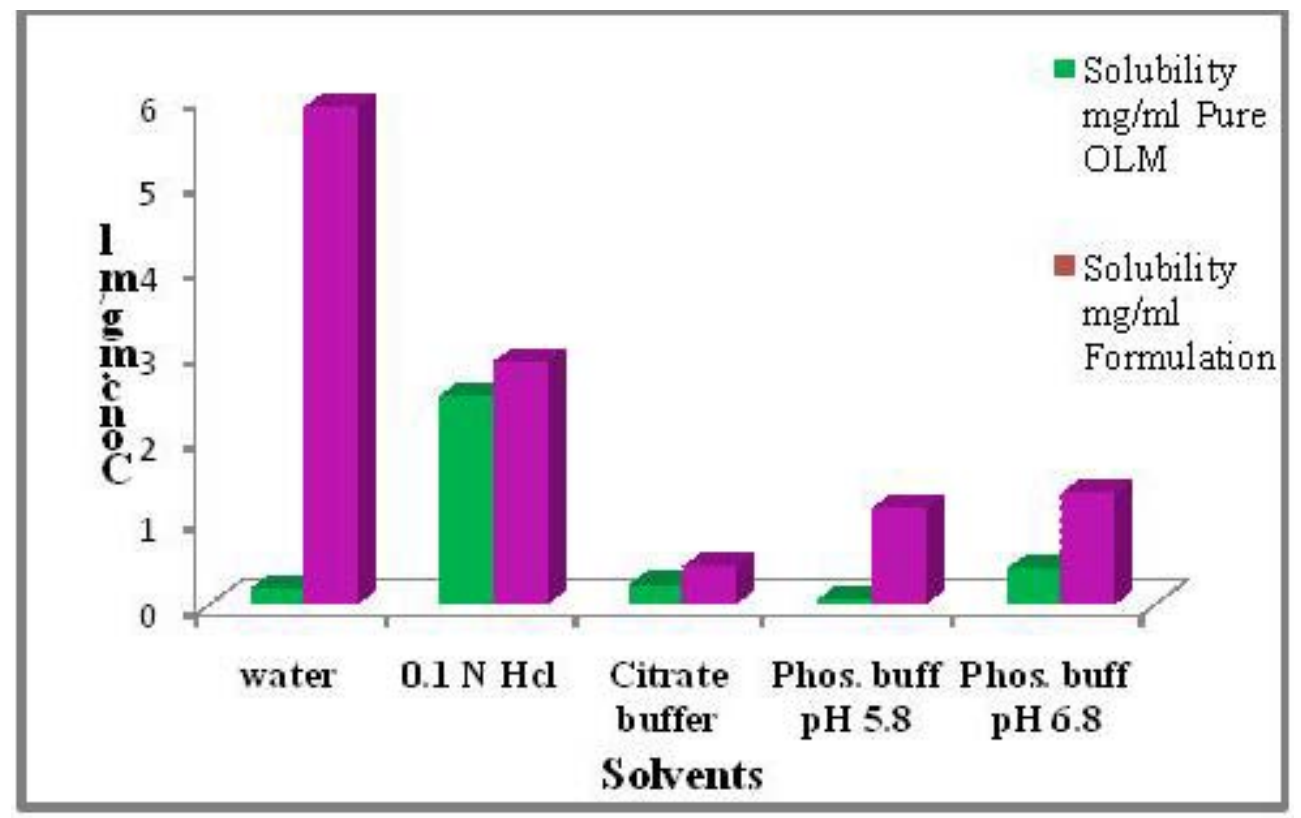

Figure 1: Solubility study of OLM and prepared OLM particles (F4) in different solvents.

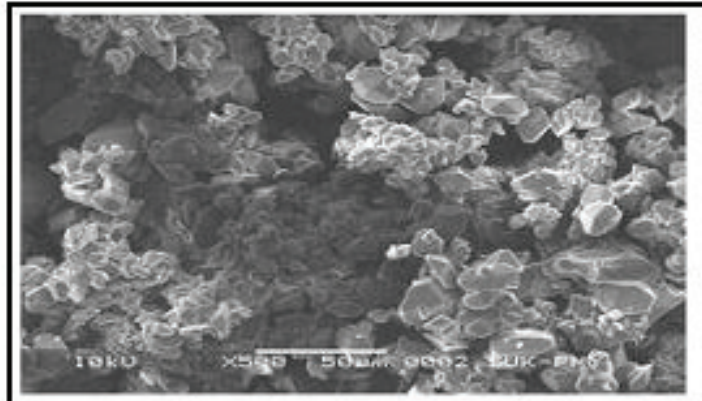

(A)

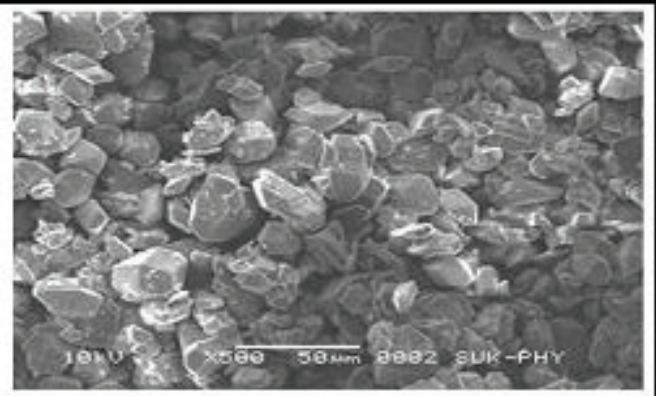

(B)

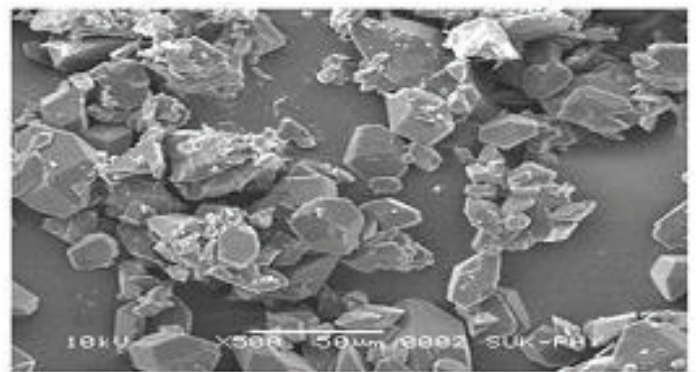

(C)

Figure 2: SEM images of OLM particles prepared with different stirring time: (a) $5 \mathrm{~min}$; (b) 1 '0 min; (c) 15 min; (OLM ethanol concentration: $30 \mathrm{mg} / \mathrm{mL}$ ).

used as polymer. It may provide steric stabilization. So, negative zeta potential was attributed for formulations. Formulation F4 complies with requirement of zeta potential for stability. ${ }^{17-18}$

\section{Drug content determination}

Drug content of formulation (F1, F2, F3, F4) was found to be $93.24 \pm 0.96,95.53 \pm 0.88,96.52 \pm 0.85$,
$99.91 \pm 0.98 \%$ respectively. Drug content of OLM was $97.5 \%-102.0 \%$ as per European pharmacopeia. Drug content of Formulation (F4) was found to be (99.91 \pm $0.98 \%$ ) which compiles requirement compared to other formulations. Hence, formulation F4 (1\%w/v Kollicoat IR) were selected for tablet preparation.Due to high concentration of Kollicoat IR in Formulation (F4) maximum amount of particles precipitated out from 


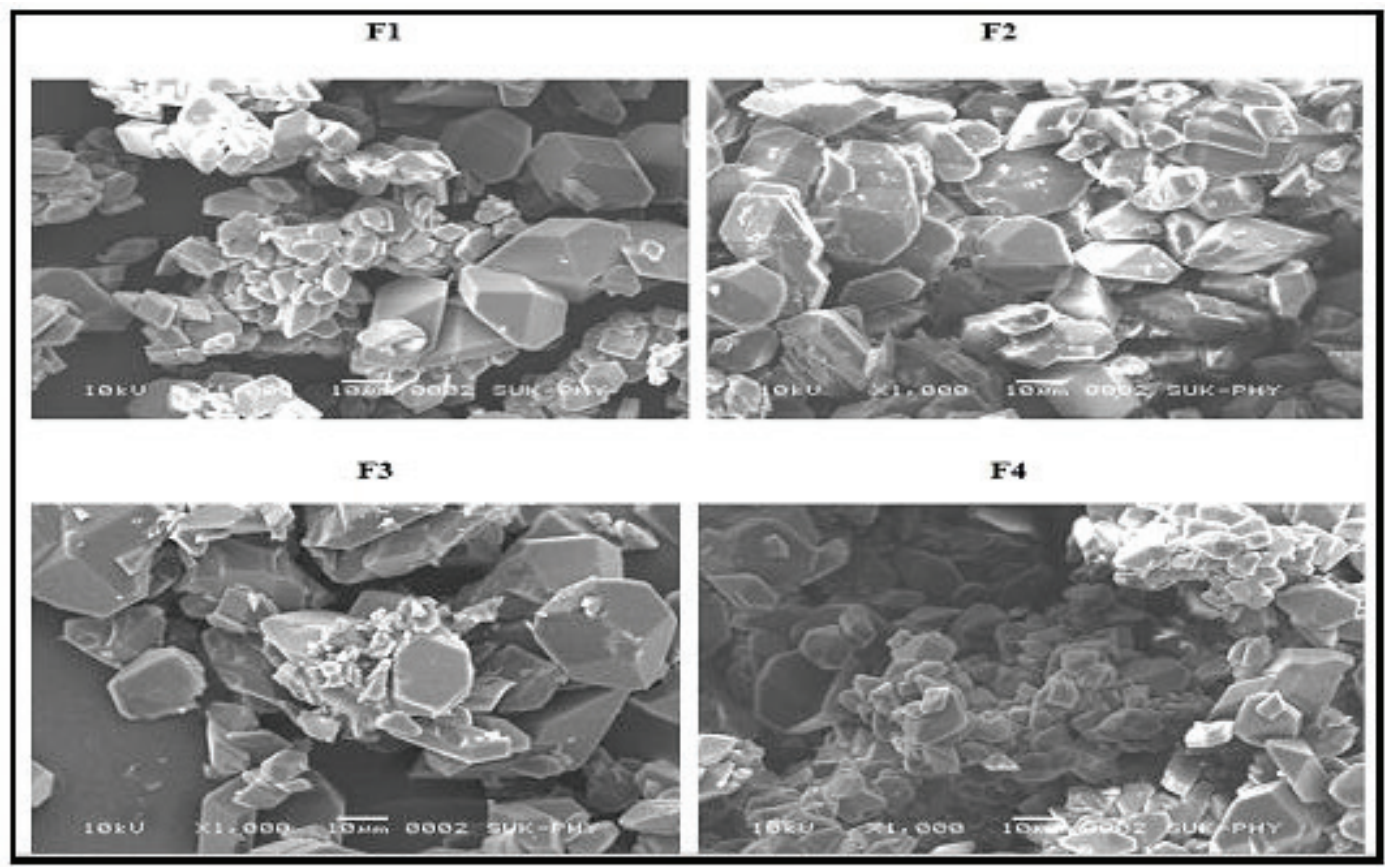

Figure 3: SEM images of OLM particles obtained with different concentration of Kollicoat IR as polymer: (F1) $0.25 \%$ (w/v), (F2) $0.5 \%(w / v),(F 3) 0.75 \%(w / v),(F 4) 1 \%(w / v)$. (OLM ethanol concentration: $30 \mathrm{mg} / \mathrm{mL})$.

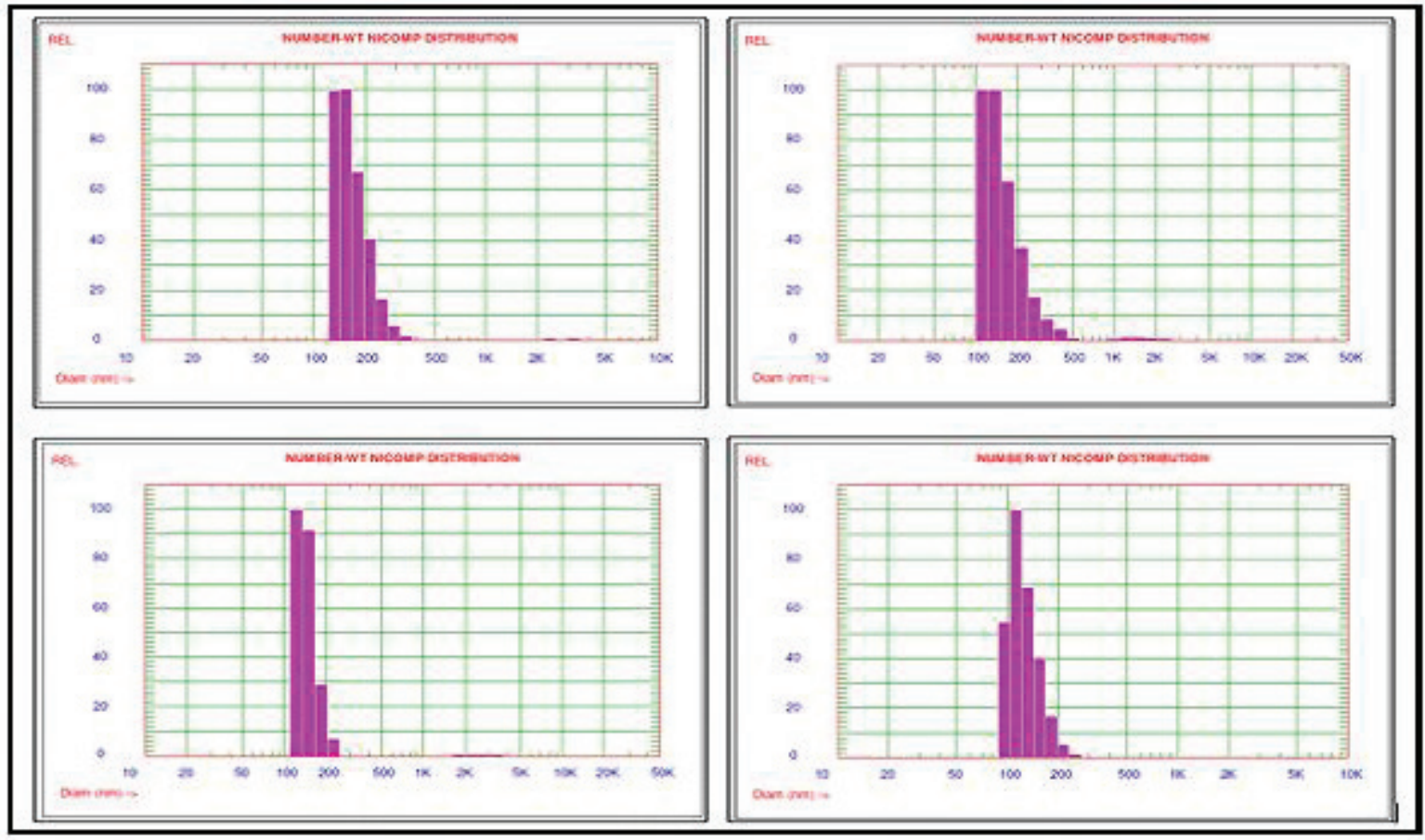

Figure 4: Particle size results of Formulations F1, F2, F3, F4.

solution with coating on surface of particles which increases product content. ${ }^{19-20}$

\section{Drug- Excipient Compatibility Studies (FTIR)}

FTIR spectrum of pure olmesartan medoxomil, physical mixture, formulation F4 (Optimized Batch)which are shown in Figure 5 IR spectra of olmesartan medoxomil showed characteristic peaks at $3301 \mathrm{~cm}-1$ (Broad-OH stretch), $1712 \mathrm{~cm}-1$ ( $\mathrm{C}=\mathrm{O}$ ketonic group), $2975 \mathrm{~cm}-1$ (C=C-C unsaturation), $1172,1139 \mathrm{~cm}-1$ (C-N Secondary amine), $1137 \mathrm{~cm}-1$ (C-O-C), $3305 \mathrm{~cm}-1$ (NH-stretch amine), FTIR spectra of physical mixture displayed 
chavan et al: Copolymer based nanoparticles of OLM

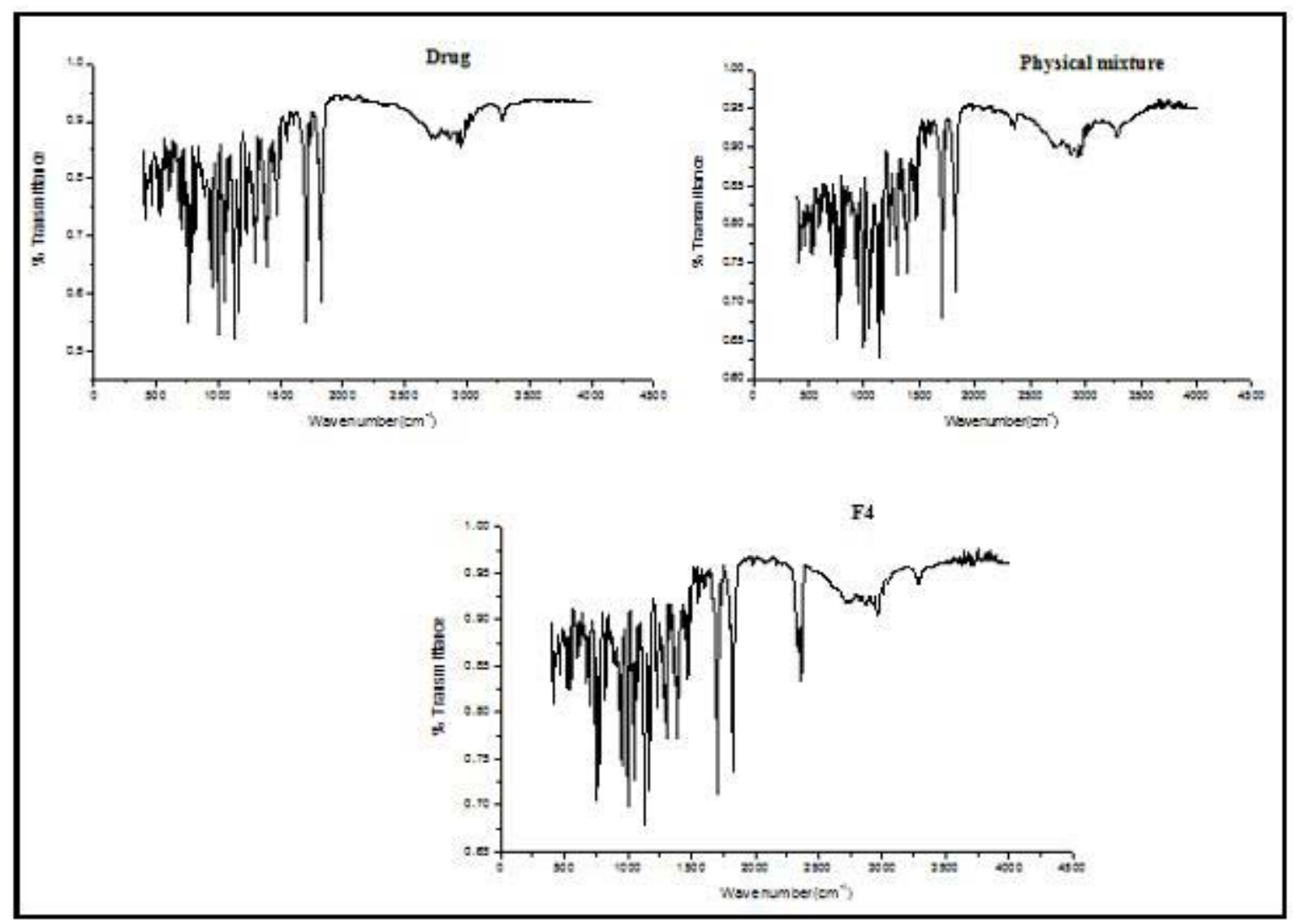

Figure 5: FTIR Spectra of Olmesartan medoxomil, physical mixture, Formulation F4 (Optimized Batch).

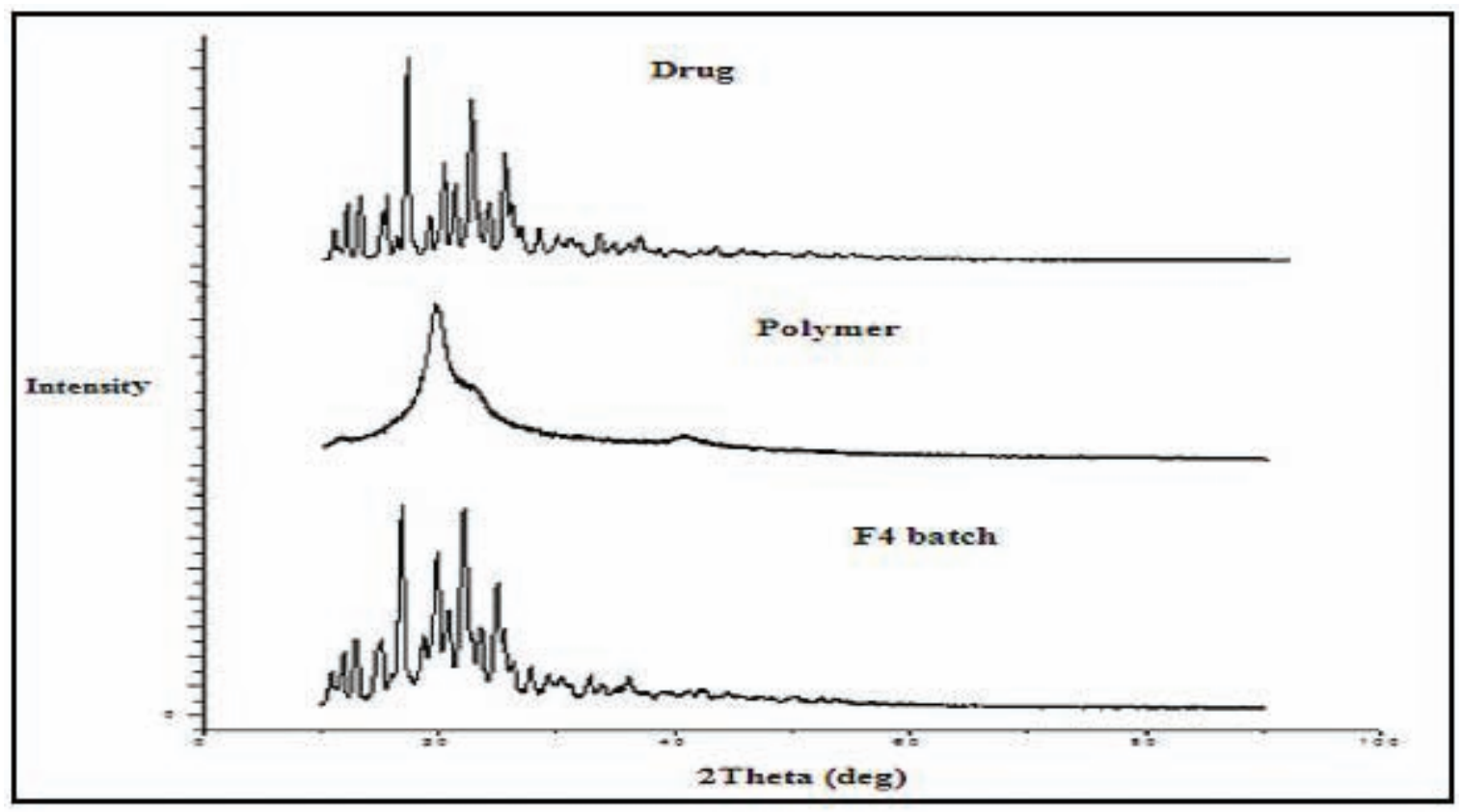

Figure 6: XRPD Pattern of Drug, Polymer, Formulation F4 (Optimized Batch).

Indian Journal of Pharmaceutical Education and Research | Vol 50 | Issue 4 | Oct-Dec, 2016

683 


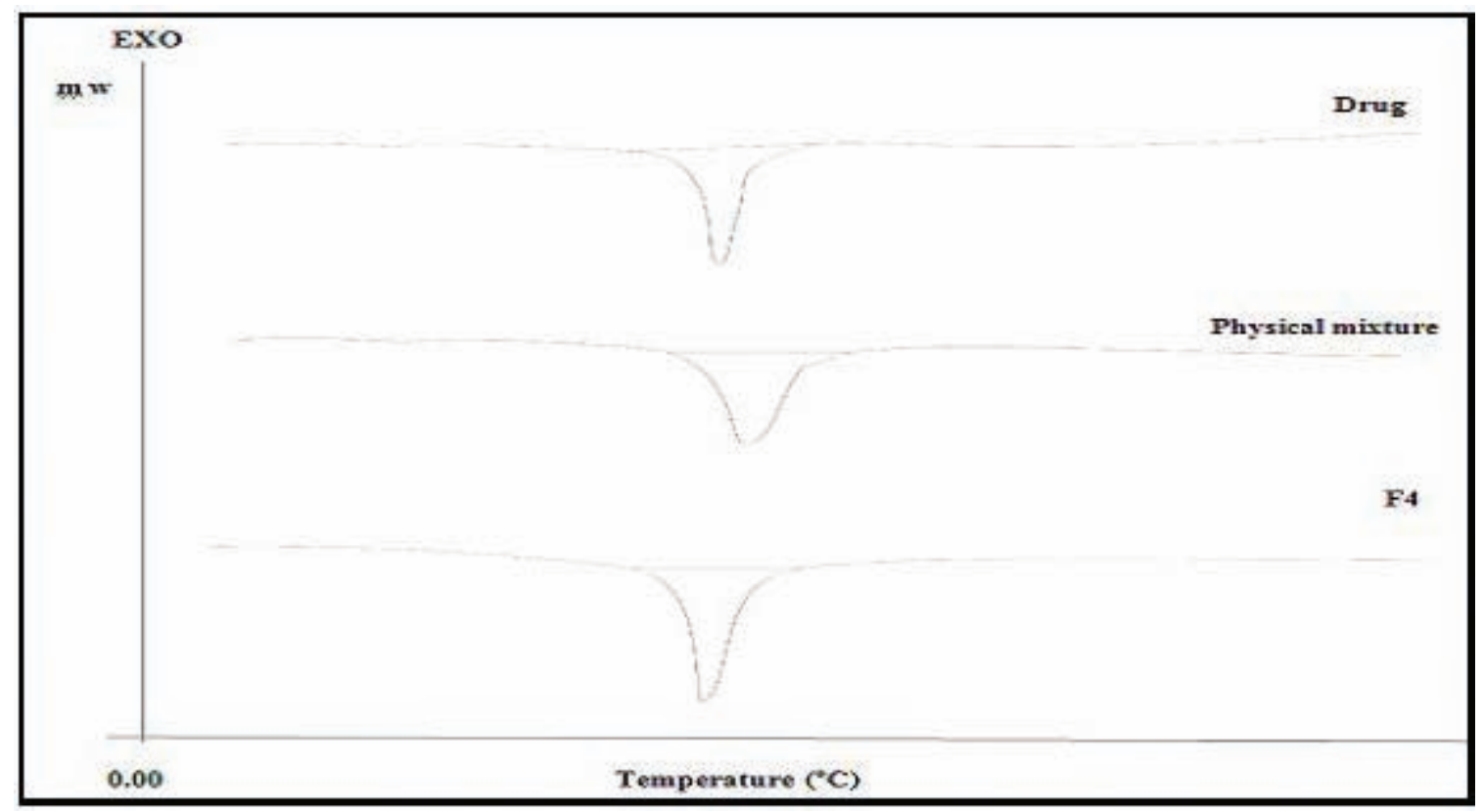

Figure 7: DSC curves of Pure OLM, Physical mixture, Fr (Optimized Batch)

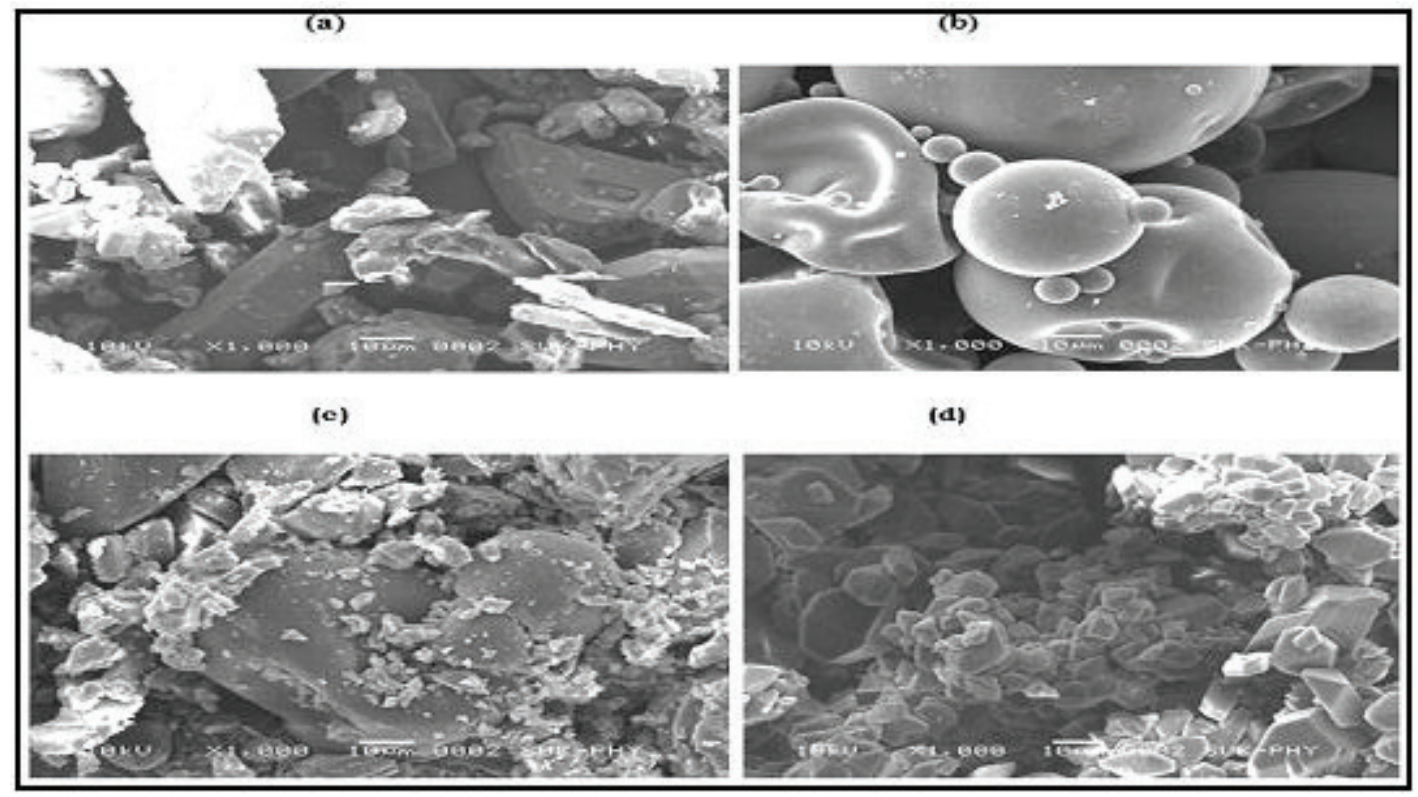

Figure 8: SEM images of (a) Drug (b) Kollicoat IR(c) Physical mixture (OLM: Kollicoat IR) (d) (Formulation F4 (Optimized Batch)

prominent peaks at $3301 \mathrm{~cm}-1$ (OH stretch), $1712 \mathrm{~cm}-1$ ( $\mathrm{C}=\mathrm{O}$ ketonic group), $1137 \mathrm{~cm}-1$ (C-O-C stretch) and $1460 \mathrm{~cm}-1$ (=C-H methylelene $\mathrm{CH}$ bend),Approx 2880 cm-1 (at high energy CHO). Formulation (F4) showed characteristic band at $3301 \mathrm{~cm}^{1}(\mathrm{O}-\mathrm{H}$, stretch, broad), $1712 \mathrm{~cm}-1$ (C=O), $1137 \mathrm{~cm}-1$ (C-O-C stretch), $2880 \mathrm{~cm}-$ 1 (at high energy $\mathrm{CHO}$ ), $3305 \mathrm{~cm}-1$ ( $\mathrm{NH}$-stretch amine). 2453-2376 (Carboxylic acid broad peak).FTIR spectra of physical mixture did not indicate any well-defined interaction between OLM \& Kollicoat IR. Therefore it can be concluded that drug and polymers were compatible with each other. FTIR spectrum of Formulation F4 (Optimized Batch) showed that there were no considerable changes in IR peaks of formulation when compared to pure OLM and no changes have occurred in their chemical structure. The strong interaction between drug and carrier, often leads to identifiable changes in IR profile of the drug but the results of IR spectra indicated an absence of any well-defined interaction between olmesartan medoxomil and Kollicoat IR. 


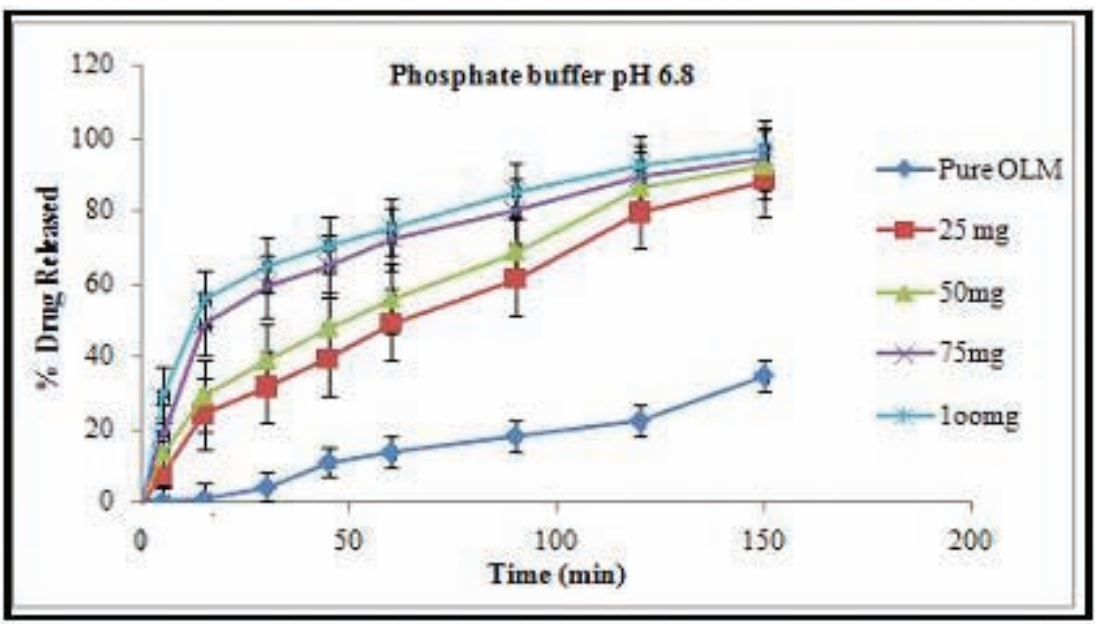

Figure 9: In-vitro Release Profile of all formulations (F1, F2, F3, F4) and Pure OLM in phosphate buffer pH6.8.

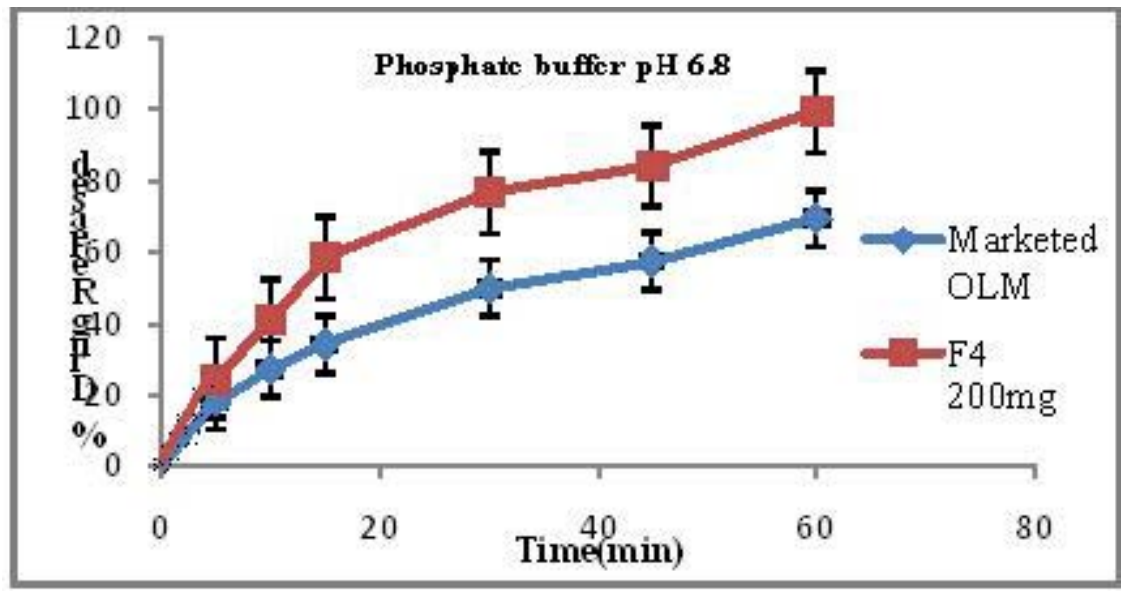

Figure 10: In-vitro Release Profile of tablets of OLM particles \& marketed tablet in phosphate buffer pH6.8.

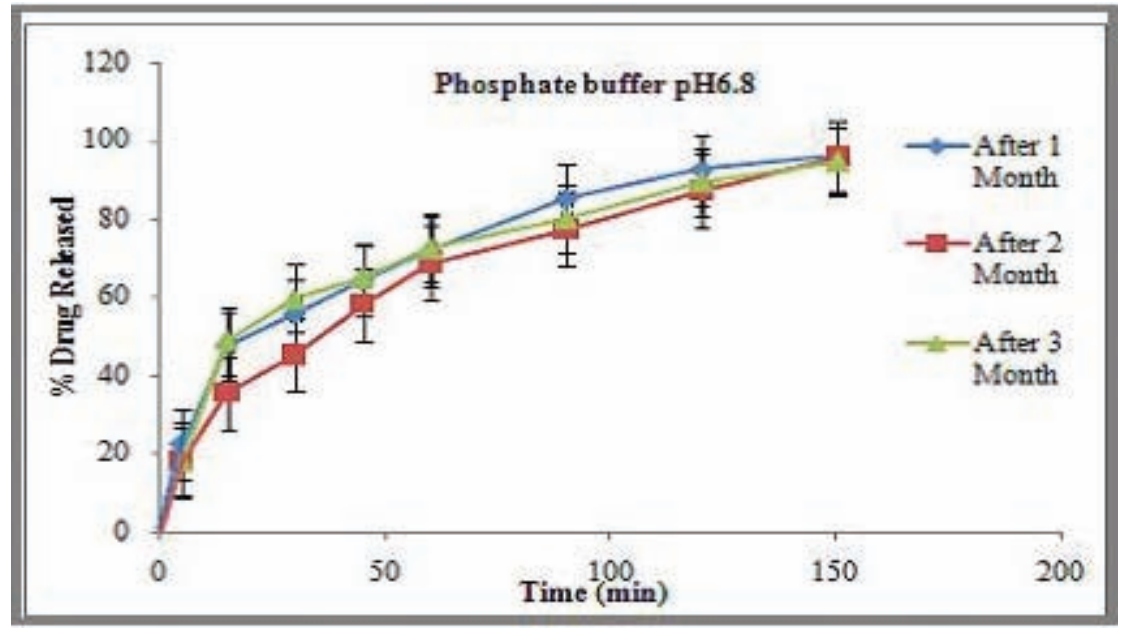

Figure 11: In-vitro Release profile of particles (After 1, 2, 3 month) in phosphate buffer pH6.8 $(\mathrm{n}=3$ ) 


\begin{tabular}{|c|c|c|c|}
\hline \multicolumn{4}{|c|}{ Table 1: Composition of OLM particles } \\
\hline Batch & $\begin{array}{c}\text { Olmesartan } \\
\text { Medoxomil }\end{array}$ & Kollicoat IR & Solvent \\
\hline F1 & $300 \mathrm{mg}$ & $25 \mathrm{mg}$ & $10 \mathrm{ml}$ \\
\hline F2 & $300 \mathrm{mg}$ & $50 \mathrm{mg}$ & $10 \mathrm{ml}$ \\
\hline F3 & $300 \mathrm{mg}$ & $75 \mathrm{mg}$ & $10 \mathrm{ml}$ \\
\hline F4 & $300 \mathrm{mg}$ & $100 \mathrm{mg}$ & $10 \mathrm{ml}$ \\
\hline
\end{tabular}

\begin{tabular}{|c|c|c|c|}
\hline \multicolumn{4}{|c|}{ Table 2: Solubility study of OLM and prepared OLM } \\
particles (F4) in different solvents. \\
\hline Sr. No. & Solvents & $\begin{array}{c}\text { Solubility } \\
\text { mg/ml Pure } \\
\text { OLM }\end{array}$ & $\begin{array}{c}\text { Solubility } \\
\text { mg/ml } \\
\text { Formulation } \\
\text { (F4) }\end{array}$ \\
\hline 1 & water* & $0.19 \pm 0.010$ & $5.888 \pm 0.833$ \\
\hline 2 & $0.1 \mathrm{~N} \mathrm{HCl}^{*}$ & $2.47 \pm 0.002$ & $0.8765 \pm 0.215$ \\
\hline 3 & Citrate buffer* & $0.229 \pm 0.006$ & $0.4526 \pm 0.405$ \\
\hline 4 & Phos. buff pH $5.8^{*}$ & $0.0642 \pm 0.018$ & $1.141 \pm 0.186$ \\
\hline 5 & Phos. buff pH $6.8^{*}$ & $0.4237 \pm 0.003$ & $1.32 \pm 0.405$ \\
\hline$*$ Indicates mean \pm SD $(n=3)$ & & \\
\hline
\end{tabular}

\begin{tabular}{|c|c|c|c|}
\hline \multicolumn{3}{|c|}{ Table 3: Particle size results of all OLM Formulations } \\
\hline Sr. No. & Formulation Code & $\begin{array}{c}\text { Mean } \\
\text { Particle size } \\
\text { (nm) }\end{array}$ & PDI \\
\hline 1 & F1 & 188.9 & 0.452 \\
\hline 2 & F2 & 187.6 & 0.546 \\
\hline 3 & F3 & 177.7 & 0.560 \\
\hline 4 & F4 & 136.3 & 0.299 \\
\hline
\end{tabular}

\begin{tabular}{|c|c|c|}
\hline \multicolumn{3}{|c|}{ Table 4: Composition of Tablets } \\
\hline Sr. No. & Ingredient & Quantity/tablet \\
\hline 1 & Olmesartan Medoxomil & $40 \mathrm{mg}$ \\
\hline 2 & Lactose monohydrate & $72 \mathrm{mg}$ \\
\hline 3 & Microcrystalline cellulose & $72 \mathrm{mg}$ \\
\hline 4 & Cross carmellose sodium & $8 \mathrm{mg}$ \\
\hline 5 & Magnesium stearate & $4 \mathrm{mg}$ \\
\hline 6 & Talc & $4 \mathrm{mg}$ \\
\hline 7 & Total weight of tablet & $200 \mathrm{mg}$ \\
\hline
\end{tabular}

\section{Powder X-ray diffraction}

PXRD used to assess degree of crystallinity of given sample. Raw OLM was highly crystallized and exhibited intense crystalline peaks at $2 \theta$ value of 16.78 with high intensity 10606.At same angle F4 (Optimized Batch) showed maximum intensity of about 6372 . Kollicoat IR showed 4388 intensity at same 20. From results it was found that Pure OLM and Kollicoat IR were in crystalline state. In case of formulation intensity of peaks was reduced, but peak pattern was not changed, drug particles exist in same crystalline state as raw OLM. It has been known that reduction of drug to down size would lead to high-energy state and high disorder, resulting in enhanced dissolution rate and bioavailability ${ }^{15}$ PXRD of Pure OLM, Kollicoat IR, F4 (Optimized Batch) shown in Figure 6.

\section{Differential scanning calorimetry}

DSC curves of Pure OLM, PM (OLM: Kollicoat IR), F4 (Optimized Batch) shown in Figure 7 DSC analysis has been used to detect all process in which energy was required or produced.DSC curve of pure OLM exhibited sharp endothermic peak at $184.73^{\circ} \mathrm{C}$ corresponding to melting of drug. While PM showed endothermic peak at $191.45^{\circ} \mathrm{c} . \mathrm{F} 4$ (Optimized Batch) showed endothermic peak at $179.87^{\circ} \mathrm{C}$ indicated decreases in energy change of melting endotherm, which confirms considerable extent of reduction in crystallinity of drug. DSC results supported XRPD data. This phenomenon could be attributed to reduction in particle size, decreased intensity of particles, which may results into decreased in melting point of particles. Fraction absorbed for drugs with high melting temperatures is limited by dose to greater degree than it is for low melting compounds. ${ }^{21}$

\section{Scanning electron microscopy}

SEM images of OLM, Kollicoat IR, PM and F4 Batch which was shown in Figure 8 Photomicrograph of drug indicated that OLM was rod shaped crystalline solid and Kollicoat IR was spherical in shape. Formulation indicated that shape of particles was regular, hexagonal with smooth surface due to coating of polymer onto surface of drug particle, which enable them to flow very easily. Pure OLM is rod cylindrical particles elongated along one axis. OLM precipitated particles were hexagonal particles with faces parallel to growth axis; width and thickness greater than acicular and shorter in length (Prismatic). ${ }^{22}$

\section{In vitro dissolution Study}

Plot of $\%$ drug released as function of time shown in Figure 9. \% drug release of Pure OLM \& F1 to F4 was $(13.84,48.92,55.95,72.47$, and $75.65 \%)$ respectively with in period of $60 \mathrm{~min}$. In vitro study showed that formulation F4 exhibited better dissolution property than others therefore it was used for further investigations. There was significant difference between dissolution rates of pure drug and particles. This increased in dissolution rate was due to increased surface area of drug due to smaller size. Increased dissolution velocity of OLM particles was in agreement with theory of dissolution by Noyes-Whitney. According to Noyes-Whitney equation, 
increased in saturation solubility, decreased in particle size lead to increased dissolution rate. So, formulation of poorly water soluble drugs as nanometer sized drug particles has drastic effect on dissolution rate, solubility, and bioavailability. Bioavailability of OLM was truly dissolution rate limited, so particle size reduction can significantly improve performance of OLM.

\section{Development of Tablets oral dosage form ${ }^{23}$}

The formula compositions chosen for tableting are shown in Table 4.

\section{Evaluation of Tablets}

The physical propertiessuch as the average weight of the tablet was found to be $200.01 \mathrm{mg}$. Tablets possessed acceptable mechanical strength with hardness of $4.50 \pm$ $0.25 \mathrm{~kg} / \mathrm{cm}^{2}$. Thickness of tablet was found to be 0.100 $\pm 0.115 \mathrm{~cm}$ and friability was found to be $0.6913 \pm 0.25$ $(\%)$ it was $<1 \%$ indicating good mechanical strength. All tablet properties meet standards within Pharmacopoeia limits.

\section{Comparison of In vitro dissolution profile of prepared tablets (OLM particles) and marketed formulation (olsertain ${ }^{\mathrm{TM}} 40$ )}

The Plot of $\%$ drug release as function of time shown in Figure 10. \% drug release of tablets of OLM particles and marketed tablet was $(99.45,69.5 \%$ respectively) within period of $60 \mathrm{~min}$. In vitro study showed that tablets of OLM particles exhibited better dissolution than marketed.This increased in dissolution rate was due to presence OLM particles.

\section{Stability study}

Optimized batch $\mathrm{F}_{4}$ was evaluated for stability study. It was conducted for 3 months; every month slightly decreased in drug content of OLM particles \&found $97.19 \pm 0.39,97.01 \pm 0.61,96.99 \pm 0.43 \%$. All limits were acceptable as per European pharmacopoeia (97.5 $\%-102.0 \%$ ) Dissolution behaviour during stability study shown in Figure 11. Percentage drug release of particles was slightly decreased. Because as time passes particle agglomeration was occurs. Initially formed particles get coagulated to larger once, which reduces surface area $\&$ dissolution rate. ${ }^{24}$

\section{CONCLUSION}

By using Polyvinyl Alcohol- Polyethylene Glycol Graft Copolymer we can enhance the dissolution rate of BCS class II molecules like OLM. This copolymer can be used for formulation of stable nanoparticles by antisolvent precipitation technology which is the simple and scalable technique but attention should be given to optimization of stirring speed and stirring time. The prepared nanoparticles showed the improvement in solubility and dissolution rate. When incorporated in a tablet dosage form showed better performance than marketed formulation (olsertain ${ }^{\mathrm{TM}} 40$ ).

\section{ACKNOWLEDGEMENTS}

Authors are grateful to Emcure Pharmaceuticals Ltd, Pune, India.for providing gift sample of drug, Lupin Pharmaceuticals Ltd, Pune, India for excipients and also to Shivaji University, Kolhapur, MH, India for providing facilities for characterization of samples. All authors express their sincere thanks to management of Shree Santkrupa College of Pharmacy, Ghogaon, Karad, MH, India for providing laboratory facilities to carry out research work.

\section{REFERENCES}

1. Devesh A, Pethe, A. Nanotechnology: A promising drug delivery for poorly water soluble drugs. Pharm Res. 2010;3(8):1748-51.

2. Keck C, Muller R, Twenty years of drug nanocrystals: Where are we, and where do we go. Eur J Pharm \& Biopharm. 2012;80(1):1-3. http://dx.doi. org/10.1016/j.ejpb.2011.09.012; PMid:21971369

3. Kohane D. Microparticles and Nanoparticles for Drug Delivery. Biotechnology and Bioengineering. 2007;96:203-09. http://dx.doi.org/10.1002/bit.21301 ; PMid:17191251

4. Katteboinaa, S, Chandrasekhar V, Balaji S. Drug nanocrystals: a novel formulation approach for poorly soluble drugs. Int J Pharm Tech Res. 2009;1(3):682-94.

5. Sawant S, Kadam V, Jadhav K, Sankpal S, Drug nanocrystals: novel technique for delivery of poorly soluble drugs. Int J Scilnnov \& Disc. 2011;1:1-15.

6. Krause K, Müller R. Production and characterization of highly concentrated nanosuspensions by high pressure homogenization. Int $\mathrm{J}$ Pharm. 2001;214(1):21-4. http://dx.doi.org/10.1016/S0378-5173(00)00626-8

7. Tenorio A, Gordillo M, Pereyra C, Martínez O. Controlled submicro particle formation of ampicillin by supercritical antisolvent precipitation. J Supercrit Fluids. 2007;40(2):308-16. http://dx.doi.org/10.1016/j.supflu.2006.07.003

8. Chiou H, Li L, Hu T, Chan H, Chen J, Yun J. Production of salbutamol sulfate for inhalation by high-gravity controlled antisolvent precipitation. Int J Pharm. 2007;331(1):93-8. http://dx.doi.org/10.1016/j.jpharm.2006.09.022; PMid:17052870

9. Zhang J,Shen Z, Zhong J, Hu T, Chen J, Yun ZJ. Preparation of amorphous cefuroxime axetil nanoparticles by controlled nanoprecipitation method without surfactants. Int J Pharm. 2006;323(1):153-60. http://dx.doi.org/ 10.1016/j.jpharm.2006.07.026 http://dx.doi.org/10.1016/j.ijpharm.2006.05.048; PMid:16828244

10. Wang Z, Chen J, Le Y,Shen Z, Yun J. Preparation of ultrafine become thasone dipropionate drug powder by anti solvent precipitation. IndEngChem Res. 2007;46(14):4839-45. http://dx.doi.org/10.1021/ie0615537

11. Zhong J, Shen Z, Yang Y, Chen J. Preparation and characterization of uniform nano sized cephradine by combination of reactive precipitation and liquid anti-solvent precipitation under high gravity environment. Int J Pharm. 2005;301(1):286-93. http://dx.doi.org/10.1016/j.ijpharm.2005.06.005; PMid:16054788

12. Thakkar H, Patel B, Parmar M, Chauhan N, Patel A. Studies on inclusion complex as potential systems for enhancement of oral bioavailability of olmesartan medoxomil. Chronicles of Young Scientist. 2012;3(2):129-36. http://dx.doi.org/10.4103/2229-5186.98685 
13. Liberman $\mathrm{H}$, Lachman L, Schwartz Pharmaceutical dosage forms tablets. $1^{\text {st }}$ ed. New York Marcel Dekker; 1990.40.

14. Higuchi T, Connors K. Phase solubility techniques, Adv Anal Chem. Instr. 1965;4:117-212

15. Chen J, Zhang H, Wang J, Zhang Z, LeY, Shen Z. Micronization of atorvastatin calcium by antisolvent precipitation process. Int J Pharm. 2009;374(1):106-13. PMid:19446766

16. Quan P, Xia D, Piao H, Piao H, Shi K, Jia Y. Nitrendipine Nano crystals: Its Preparation, Characterization, and In vitro - In vivo Evaluation. AAPS Pharm Sci Tech. 2011;12(4):1136-43. http://dx.doi.org/10.1208/s12249-011-9682-2; PMid:21892695 PMCid:PMC3225555

17. Riddick, T. Zeta-Meter operating Manual. Zeta-Meter Inc., New York: 1968. PMid:5671014

18. Thakkar H, Patel B, Thakkar S. Development and Characterization of nanosuspensions of olmesartan medoxomil for Bioavailability enhancement. J Pharm \& Bioallied Sci. 2011;3(3):426-34. http://dx.doi.org/10.4103/09757406.84459; PMid:21966165 PMCid:PMC3178951
19. Karekar P, Yadav A, Yadav AV, Pore YV, Gajare P. Enhanced solubility and dissolution rate of Olmesartan medoxomil using Crystallo-co-agglomeration technique. Pelagia Research Library. 2012;3(2):160-9.

20. Tayseer E, Abdel M, Dalia G, Samia N. Solubility enhancement of olmesartan by utilization of solid dispersion and complexation techniques. Int J Novel Drug Deliv Tech. 2012;2:297-303

21. Chu K, Yalkowsky S. An interesting relationship between drug absorption and melting point. Int J Pharm. 2009;373(1):24-40. http://dx.doi.org/10.1016/j ijpharm.2009.01.026; PMid:19429285

22. Wenju W, Nancollas G. A new understanding of the relationship between solubility and particle size. J Solution Chem. 1998;27(6):521-31. http://dx.doi. org/10.1023/A:1022678505433

23. Nekkanti V, Pillai R, Venkateshwarlu V, Harisudhan T. Development and characterization of solid oral dosage form incorporating candesartan nano particles. Pharma Dev and Tech. 2009;14(3):290-8. http://dx.doi org/10.1080/10837450802585278; PMid:19235553

24. Verma P, Kamboj V, Ranjan S. Spectrophotometric Estimation of Olmesartan Medoxomil in Tablet Dosage form with Stability studies. Int J Chem Tech Res. 2010;2:29-1134

\section{SUMMARY}

- kollicoat IR can be used for formulation of nanoparticles 2. formulated nanoparticles of OLM showed improved dissolution rate 3 . stirring time and speed are important parameters which affects on morphology of particles.

\section{About Authors}

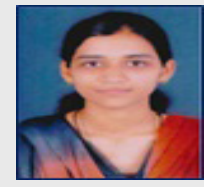

Miss. Aparna Ashok chavan: Completed (B. Pharm) 2011 and M.Pharm in Pharmaceutics from Shree Santkrupa College of Pharmacy, Ghogaon, Shivaji University, Kolhapur (MS) India in 2013.

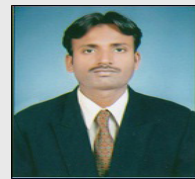

Mr. Amol Somanath Shete: Presently he is working as an assistant professor and Head department of pharmaceutics at shree Santkrupa college of pharmacy, Ghogoan. His area of interest is crystal engineering, evaluation of natural substances as pharmaceutical excipients, particulate drug delivery system.

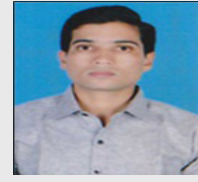

Mr. Bhagyesh Uttamrao Janugade: Presently he is working as an assistant professor in department of pharmaceutics at Shree Santkrupa college of pharmacy, Ghogoan. His area of interest is pulsatile drug delivery systems, targeted and chrono modulated drug delivery devices.

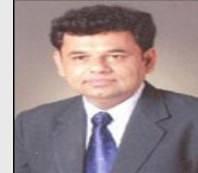

Dr. Rajendra Chandrashekar Doijad: Presently working as Principal \& Professor at Shree Santkrupa College of Pharmacy, Ghogaon-Karad. He has presented scientific research papers at various international conferences. His area of interest is resealed erythrocytes and particulate drug delivery system. 